\title{
Revisto \\ HOSPITALIDADE \\ ISSN 1807-975X \\ O jogo Pokémon Go e as características que o tornam um potencial promotor de vendas em negócios de turismo e alimentos e bebidas.
}

\section{The game Pokémon Go and the features that make it a sales promoter potential in tourism and food $\&$ beverage businesses.}

El juego Pokémon Go y las características que lo convierten en un potencial promotor de ventas en empresas de turismo y de alimentos y bebidas.

Resumo: Surgidos na década de 1970, os jogos eletrônicos disseminaram-se de forma crescente pelo mundo e seus adeptos já chegaram a centenas de milhões de jogadores. Dentro deste cenário o surgimento do jogo Pokémon Go constituiu-se como um fenômeno a parte, tanto pela tecnologia empregada - a realidade aumentada direcionada a smartphones - como pelos números recordes de downloads ocorridos. Pela característica de retirar os jogadores dos ambientes fechados e fazê-los circular, aos milhares, por espaços públicos, tornou-se este jogo um potencial promotor de vendas de diversos negócios, entre eles aqueles ligados ao turismo e à oferta de alimentos e bebidas aqui focados. O objetivo deste trabalho foi o de, a partir de pesquisa exploratória de natureza qualitativa, avaliar o potencial do jogo como promotor das vendas nestes negócios, assim como ilustra-lo com relatos daqueles que já empreenderam promoções com tal finalidade. Ainda que, devido à natureza recente do objeto estudado não se dispusesse de contabilidade ou dados que comprovassem sua eficácia, observou-se que o jogo tem sido sentido por comerciantes como um potencial promotor de seus negócios.

Palavras chave: Jogos eletrônicos; Pokémon Go; Realidade aumentada; Turismo; Alimentos e bebidas.

Abstract: Electronic games emerged in the 1970s have spread increasingly throughout the world. Their supporters have already reached hundreds of millions of players. Within this scenario the Pokémon Go game appearance was constituted as a phenomenon as a result of two main factors: the technology employed based on "augmented reality" directed at smartphones and as the record numbers of downloads occurred. For its feature to remove players from indoors and have then circulating through public spaces, the game has become a potential sales promoter of several businesses including those related to tourism and food $\&$ beverage related ones which are the focus of this paper. Through an exploratory qualitative study this paper aimed to understand the

\footnotetext{
1 Graduação e DESS em psicologia pela Université René Descartes, Paris V, S.H. Sorbonne. Mestre em Hospitalidade pela Universidade Anhembi Morumbi. Filiação profissional: Universidade Anhembi Morumbi. Link de acesso a $\quad$ Currículo Lattes:http://lattes.cnpq.br/0686651121592895 luizgacarvalho@anhembimorumbi.edu.br.

${ }^{2}$ Graduado em engenharia pela Escola Politécnica da USP. Mestre em filosofia pela Faculdade São Bento. MBA pela Fundação Getulio Vargas (FGV). Psicanalista pela Sociedade Paulista de Psicanálise. Filiação profissional: Business School São Paulo (BSP). Link de acesso ao Currículo Lattes: http://lattes.cnpq.br/4300529881127811. Email: gilberto@gg-guimaraes.com.br.
} 
game's potential as a promoter of sales in these businesses and to illustrate examples of those who have already undertaken promotion for this purpose. Due to the recent nature of the studied object accounted data was not yet available to support its efficiency but through this study it was observed that the game has been felt by traders as a potential promoter of their business.

Key words: Pokémon Go; Electronic games; Tourism; Food and beverage.

Resumen: Los juegos electrónicos nacieron en la década de 1970, se han diseminado por el mundo de forma creciente y hoy, sus adeptos ya han llegado a centenas de millones. Dentro de este escenario el surgimiento del juego Pokémon Go se constituye en un fenómeno aparte, tanto por la tecnología utilizada - realidad aumentada direccionada a teléfonos inteligentes - como por los records en el número de downloads realizados. Por ser un juego que retira a millares de jugadores de ambientes cerrados y los hace circular por espacios públicos este juego se tornó un potencial promotor de ventas de diversos negocios, entre ellos, aquellos direccionados al turismo y el suministro de alimentos y bebidas. El objetivo de este trabajo fue de, através de una investigación exploratoria de orden cualitativa, estudiar el potencial del juego como promotor de ventas en este tipo de negocios, así como ilustrarlo con relatos de aquellos que ya realizaron promociones en este ámbito. Aúnque, debido a la naturaleza de nuestro objeto de estudio ser poco estudiado y no haber estadísticas que prueben su eficiencia, se observó que el juego ha sido sentido por algunos comerciantes como un potencial impulsor de sus negocios.

Palabras clave: Juegos electrónicos; Pokémon Go; Realidad aumentada; Turismo; Alimentos y Bebidas.

\section{INTRODUÇÃO}

Desde o lançamento do primeiro jogo eletrônico, o Magnavox Odissey em 1972, o qual vendeu 330.000 unidades, essa modalidade de divertimento não parou de crescer. Dez anos depois, em 1982, o Nintendo Entertainment System (NES) já venderia 1.910 .000 unidades em cerca de três anos. No ano de 2.000 o Sony Playstation 2000 alcançaria a cifra exponencialmente maior de 154 milhões de aparelhos vendidos, sendo 980 mil em apenas 2 dias, estabelecendo um recorde até hoje não batido para jogos em console. Abaixo do recorde, mas, com cifras ainda expressivas o jogo Nintendo Wii lançado em 2006, atingiu a venda de quase 99 milhões de aparelhos vendidos (SCHMIDT, 2016).

Uma das causas apontadas para justificar o sucesso de adesões aos jogos eletrônicos está no fato de que neles o jogador é o principal protagonista da estória. Ao contrário dos filmes, nos quais a câmera e as imagens decorrentes não podem ser controladas pelo espectador, nesses jogos 
existe a possibilidade de interação com a tela: o jogador controla a câmera e estabelece as estratégias correspondentes (UOL SELECT GAME, 2006).

O surgimento do Pokemon Go, em 2016, com tecnologia voltada para smartphones confirmaria a importância que assumem esses jogos como entretenimento de uma parcela significativa da população. Além de estabelecer recordes de downloads do aplicativo em todos os países em que foi lançado, o Pokémon Go mostraria um potencial ainda não visto nos jogos anteriores. Concebido para ser utilizado em espaços externos, o aplicativo retirou o jogador de seu lugar habitual - recintos fechados à frente de um computador ou módulo de jogo - e o fez percorrer logradouros da cidade. Assim fazendo, o jogo, pelas suas características intrínsecas, que associa regras e pessoas em momentos de lazer, mostrou-se como potencial promotor de diversos negócios que podem estar associados às necessidades de consumo de jogadores em deslocamento urbano ou interurbano, como aqueles relacionados ao turismo e alimentos, e bebidas.

O jogo Pokémon Go utiliza tecnologia baseada na "realidade aumentada" a qual, de acordo com Azuma (1997) combina objetos reais e virtuais em um ambiente real e em tempo real e, além disso, registra e alinha esses objetos reais e virtuais uns com os outros. Para o autor, a realidade aumentada é um sistema que apresenta três características: combina o real com o virtual; é interativa em tempo real; e ajusta os objetos virtuais no ambiente 3D (AZUMA, 1997). Neste trabalho, efetuaremos, primeiramente, uma análise das origens do jogo Pokémon Go e sua relevância dentro do mundo dos jogos eletrônicos, considerando o número de adesões que obteve. Analisaremos a seguir as regras e características específicas do jogo com a finalidade de demonstrar de que forma estas o transformam em um potencial promotor de vendas. Por fim, estaremos reproduzindo sugestões de sites especializados em negócios direcionados ao aproveitamento do jogo de Pokémon Go, que, pelas suas características estimula o deslocamento de jogadores, o que é apontado como fator de incremento das vendas, apresentando, igualmente, exemplos de promoções já realizadas com tal finalidade pelo mundo. 


\section{METODOLOGIA}

Trata-se de uma pesquisa exploratória de natureza qualitativa, realizada a partir de revisão da literatura, seguida de uma sondagem empírica desenvolvida a partir de visitas a dois pontos de concentração de jogadores (Parques Ibirapuera e Trianon em São Paulo) e a duas empresas que lançaram promoções relacionadas ao jogo.

De acordo com Dencker (2001, p. 59):

[...] estudos exploratórios são investigações de pesquisa empírica que têm por finalidade formular um problema ou esclarecer questões para desenvolver hipóteses. $\mathrm{O}$ estudo exploratório aumenta a familiaridade do pesquisador com o fenômeno ou com o ambiente que pretende investigar, servindo de base para uma pesquisa futura mais precisa.

Devido à natureza do objeto estudado, a revisão da literatura se processou, maiormente, pela internet, mídia que concentra na atualidade a boa parte das informações sobre o jogo. As pesquisas empíricas visaram o contato com os jogadores de Pokémon Go e com empresas envolvidas em promoções ou serviços direcionados ao jogo e seus aficionados na cidade de São Paulo. Decorre do pouco tempo, desde a implantação do jogo no Brasil, a escassa informação sobre o mesmo e o pequeno número de empresas envolvidas em promoções direcionadas a ele, ou então, que já tenham percebido seu potencial comercial. Por esta razão a amostra estudada constitui-se como não probabilística tratando-se de uma amostra definida pela população mais acessível ao pesquisador (MATTAR, 1996).

Observou-se, durante as visitas efetuadas a parques, que os jogadores se utilizam das nomenclaturas inglesas do jogo para alguns itens e de suas versões para outros. Emprega-se, por exemplo, a palavra "lures" referindo-se às poções que atraem pokémons e não "iscas" como seria a versão mais próxima do termo inglês para o contexto. Ao mesmo tempo, utilizam mais a palavra "incubadora" do que "incubator" sua correspondente em inglês. Por esta razão adotamos neste trabalho nomenclaturas conforme seu uso mais difundido entre os jogadores. 


\section{A POPULARIZAÇÃO DOS JOGOS ELETRÔNICOS}

Jogos eletrônicos deixaram de ser atividades de lazer infanto-juvenis para serem adotados por todas as gerações. A esse respeito, Kenski (2003) lembra que adeptos dos fliperamas e Atari dos anos 80 são agora adultos que não abandonaram o hábito. Ilustra tal afirmação o fato de que nos Estados Unidos apenas 27\% dos videogamers possuem menos de 18 anos enquanto $44 \%$ possuem 36 anos ou mais (STATISTA, 2016). Já no Brasil, estudos feitos em 2012 revelaram que enquanto 39,4\% dos jogadores possuíam entre 12 e 19 anos, 24,4\% dos jogadores se situavam na faixa etária mais adulta, entre 25 e 34 anos (IBOPE, 2012).

A indústria de games global projeta um faturamento de mais de U\$ 100 bilhões para o ano de 2017 conforme o levantamento feito pelo banco de investimentos de produtos digitais Digi-Capital (FERREIRA, 2016). Tais cifras são tão mais significativas quando se leva em conta que em 2015 houve queda no faturamento devido à crise econômica vivenciada por países do grupo BRICs como Brasil e Rússia.

Exposições de videogames tem movimentado números crescentes de participantes presenciais e a distância. A Penny Arcade Expo realizada em 2013 reuniu em Seattle, USA, cerca de 70.000 gamers, que esgotaram seus ingressos em menos de 6 horas para compartilhar interesses, conhecer novos títulos e ouvir seus ídolos (MADIGAN, 2016).

Em 2013 a arena Staples Center de Los Angeles, tradicional local de jogos de basquete e shows, teve seus cerca de 20.000 lugares ocupados enquanto outros 5 milhões de gamers acompanhavam um campeonato internacional do League of Legends através do site Twich, especializado em transmissões de partidas de videogame em tempo real pela internet.

No Brasil a competição final do mesmo jogo reuniu em agosto de 2015 cerca 12.000 pessoas no Allians Park, estádio sede da Sociedade Esportiva Palmeiras, em São Paulo.

As cifras do Pokemon Go, objeto deste estudo, são, todavia, mais significativas.

Os valores relativos ao jogo superam o histórico de adesões pela internet em outros aplicativos: na primeira semana do lançamento do jogo nos Estados Unidos o número anunciado de downloads variou de 17 a 30 milhões, continuando a crescer entre julho (mês do lançamento) e agosto de 2016. A revista Exame em sua edição de 17 de agosto de 2016, em reportagem sobre o jogo e a realidade aumentada (tecnologia que serve de suporte ao Pokémon Go) informa cifras 
de 100 milhões de downloads pelo mundo (APP ANNIE apud EXAME, 2016) . Menos de uma semana depois, em 23 de agosto o site Redbull de Portugal estimaria o número jogadores em cerca de 200 milhões de pessoas (SILLIS, 2016). Duas semanas depois, em 7 de setembro, durante o lançamento do Iphone7 Tom Cook, CEO da Apple, afirmou que o jogo já havia sido baixado mais de 500 milhões de vezes em smartphones e seus jogadores já haviam caminhado mais de 4,6 bilhões de quilômetros atrás dos pequenos monstrinhos disponibilizados pelo aplicativo (PEREZ, 2016).

No Brasil, o jogo, lançado em 3 de agosto de 2016 teve mais de 50 milhões de acessos nas primeiras 24 horas, segundo os sites uai.com.br (2016) e pokemongobr.sw-zn.com (2016).

\section{O POKÉMON GO E SUAS CARACTERÍSTICAS}

O jogo Pokémon Go foi criado pela empresa norte americana Niantic surgida a partir de uma startup da Google.

Não foi o primeiro a empregar a realidade aumentada, já utilizada em diversos setores de atividade e nem mesmo o primeiro jogo a utilizar tal tecnologia pela Niantic. Esta empresa já havia lançado anteriormente o game Ingress, em 2012, no qual jogadores se envolviam em batalhas, tendo como ambientação elementos do mundo real, captados pelas câmeras de seus celulares. Foram contabilizados cerca de 15 milhões de downloads deste jogo (SANTOS, 2013).

O proprietário da Niantics, John Hanke havia trabalhado para a Google onde comandou o desenvolvimento do projeto Google Maps and Earth. Com a reestruturação da Google em 2015 a Niantics se torna independente sob o comando de Hanke (TAKAHASHI, 2016).

A origem da ideia do Pokémon Go deriva de um vídeo publicitário lançado pela Google em 2014, cuja a finalidade era recrutar talentos para a empresa de uma forma atrativa. Tratou-se do Google Maps: Pokémon Challenge vídeo que convidava os candidatos a explorar territórios utilizando-se do Google Maps para encontrar pokémons selvagens espalhados por suas áreas. O aplicativo surpreendeu os dirigentes ao obter18 milhões de visualizações. A oportunidade, percebida por Hanke, a qual se tornaria o grande diferencial do Pokémon Go foi a de explorar os espaços externos urbanos e interurbanos, que a plataforma propiciaria, para tirar os jogadores de casa e colocá-los à procura de personagens do jogo agregados àquela realidade espacial (BOLDRINI, 2016). O benefício colateral de tal plano seria o de incentivar a atividade física e 
promover a sociabilidade não virtual (TAKAHASHI, 2016). Tal objetivo parece ter sido atingido ao levar-se em conta os 4,6 bilhões de quilômetros que seus jogadores andaram pelo mundo apenas 2 meses após o lançamento do jogo, conforme visto anteriormente.

Henke associou-se então a Tusunekazu Ishihara, ele mesmo um jogador de Ingress para criar o Pokémon Go (TAKAHASHI, 2016).

A série que deu origem aos pokémons foi criada no Japão em 1997, por Satoshi Tajiri para o console de vídeogame Gameboy da Nintendo. Posteriormente foi lançada como história em quadrinhos (animé) e como desenho animado para televisão. A notar que o Pokémon Go de nossos dias utiliza os mesmos personagens daqueles desenhos animados e o mesmo apelo ao impulso de colecionar/acumular já presente nessas versões, elementos familiares portanto, de seus adeptos, agora adultos, observados hoje nos parques à procura dos monstrinhos.

O nome "pokemon" (contração de "pocket monster") só foi adotado durante o lançamento do jogo nos Estados Unidos com a finalidade de se encontrar uma denominação mais simples, mas igualmente para evitar a associação do nome original com um fenômeno acidental ocorrido no Japão, quando algumas centenas de crianças portadoras de arritmia cerebral sofreram convulsões ao fixarem seus olhares em um desenho animado no qual flashes de luzes coloridas piscavam em uma frequência que se revelou nociva aos seus sistemas nervosos mais vulneráveis (MASSARANI, 2016).

O Pokemon Go, a partir do uso de uma câmera de smartphone e do sistema GPS da plataforma Google Maps, integra elementos do mundo real com imagens virtuais geradas pelo aplicativo do jogo. O jogo funciona dentro de uma mecânica do tipo RPG (Role Playing Game) na qual um personagem que representa o jogador (chamado igualmente de treinador) deve capturar e fazer "evoluir" (transformando em seres mais experientes e fortes, logo mais aptos para competir) o maior número possível de monstrinhos (LEVY, 2016). Segundo o site O Vicio (OLIVEIRA, 2016) “quem está jogando Pokémon GO, tem apenas três objetivos: chegar ao nível máximo de treinador, evoluir e fortalecer seus Pokémons para atacar ginásios e completar a pokédex" (sistema que cataloga os pokémons capturados).

Para capturar monstrinhos o jogador deve circular por logradouros da cidade (que pode ser um edifício público ou privado, uma praça, um monumento ou simplesmente, costuma ocorrer, nas dependências de um pequeno negócio) nos quais o aplicativo do jogo disponibiliza monstrinhos diversos. Capturam-se pokémons arremessando sobre eles pokébolls, bolas dentro 
das quais estes devem permanecer. Uma vez capturados os monstrinhos são registrados nos pokédex que inventaria os pokémons capturados pelo jogador. (LEVY, 2016). Faz parte igualmente, da essência do jogo o fato de que os pokémons não se distribuam uniformemente pelos espaços geográficos. Sua disponibilidade pode variar de acordo com a localidade sendo alguns encontrados mais facilmente em determinadas cidades e há também aqueles exclusivos de certos países. Dentro dos municípios variam segundo os logradouros sendo os mais raros e valorizados mais frequentes em espaços mais urbanizados e simbólicos da cidade como museus e monumentos (OLIVEIRA, 2016).

Para que um pokémon evolua o jogador deve acumular candies (balas) obtidas com a captura de mais monstrinhos ou com a chocagem de ovos. Para cada tipo de monstrinho há um candy específico que o faz evoluir.

Um símbolo azul sobre um local do mundo real representado pelo mapa da tela de um smartphone, indica que ali se encontra um Pokéstop onde se pode encontrar pokeballs, ovos ou poções. Elementos que atraem pokemons, os lures (iscas) ou incensos colocados em um determinado pokestop podem ser comprados da operadora do jogo (LEVY, 2016) o que constitui como uma das fontes de renda para a Niantic e Nintendo.

Outra atividade possível do jogo é a de adquirir ovos de pokémons em um pokestop que podem ser chocados e assim transformados em monstrinhos. Mas, reside aqui outra peculiaridade do jogo: para que os ovos sejam chocados o jogador é obrigado a caminhar a pé distâncias entre 2 a 10 quilômetros. A fim de evitar que os jogadores mais resistentes a exercícios físicos burlem a necessidade de caminhadas utilizando-se de veículos motorizados, um controle de deslocamento pelo sistema GPS interrompe evolução de um ovo sempre que a velocidade do jogador deixar de ser compatível com a do andar a pé. Patins ou bicicletas utilizados vagarosamente são igualmente aceitos pelo sistema (HAMANN, 2016).

$\mathrm{Na}$ medida em que, após o jogador atingir o nível 5 do jogo (o que ocorre de acordo com o número de pokemons registrados no pokedex) este já pode frequentar um ginásio e colocar seus pokémons para disputar o lugar com aqueles pertencentes a outra equipe. (LEVY, 2016).

Sendo o aplicativo baixado gratuitamente em smartphones as empresas proprietárias do jogo buscam receitas com a venda de produtos que propiciam maior eficiência. Para compra dos diversos produtos se utilizam os pokecoins, moeda virtual que para ser comprada necessita de 
dinheiro real (LEVY, 2016). Com 0,99 centavos de dólar compra-se 100 pokecoins. Com 99,99 dólares se compram 14.500 pokécoins (TECHTUDO, 2016).

Quadro 01: Produtos vendidos no Pokémon Shop:

\begin{tabular}{|l|l|}
\hline Bag upgrade (mochila) & $\begin{array}{l}\text { Aumenta o número de itens que pode ser } \\
\text { carregado. Custo: 200 pokécoins. }\end{array}$ \\
\hline Egg Incubator (incubadora de ovos) & $\begin{array}{l}\text { Custo 150 pokécoins. Aparelho para incubar } \\
\text { ovos durante as caminhadas. }\end{array}$ \\
\hline Incense (incenso) & $\begin{array}{l}\text { Atrai pokémons para perto do treinador. Custo: } \\
80 \text { pokécoins a unidade ou 1250 pokécoins } 25 \\
\text { unidades. }\end{array}$ \\
\hline Lucky egg (ovo da sorte) & $\begin{array}{l}\text { Dobra a experiência do treinador por 30 } \\
\text { minutos. Custo: 80 pokécoins a unidade ou } \\
1250 \text { pokécoins 25 unidades. }\end{array}$ \\
\hline Lures module. (Módulo de atração) & $\begin{array}{l}\text { Atrai pokemons para um pokéstop por 30 } \\
\text { minutos. Custo: 100 pokécoins a unidade ou } \\
680 \text { pokécoins 25 unidades. }\end{array}$ \\
\hline Pokeballs (pokébolas) & $\begin{array}{l}\text { Bolas usadas para capturar pokémons. Custo: } \\
100 \text { pokécoins 20 unidades até 800 pokécoins } \\
\text { 200 unidades. }\end{array}$ \\
\hline Pokémon Go plus. & $\begin{array}{l}\text { Pulseira que alerta quando há aparecimento de } \\
\text { algum pokémon nas proximidades dispensando } \\
\text { da necessidade de o jogador olhar para o } \\
\text { smartphone. Preço estimado em 35 dólares. } \\
\text { (Pokémon Go Brasil, 2016) }\end{array}$ \\
\hline $\begin{array}{l}\text { Pókemon storage upgrade (aumento } \\
\text { da capacidade de armazenamento) }\end{array}$ & $\begin{array}{l}\text { Multiplica por 50 o número de pokémons } \\
\text { carregados. }\end{array}$ \\
\hline
\end{tabular}

Fonte: VINHA-TECHTUDO (2016)

\section{POKÉMON GO COMO POTENCIAL PROMOTOR DE VENDAS}

A condição "on line" de um jogador perseguindo a "realidade aumentada" de um pokémon na tela de seu smartphone, conjugada com sua condição "off-line" presente em um espaço público real compõe o quadro ideal para a aplicação de uma das importantes estratégias de marketing da atualidade conhecida por "Online to Offline" (O2O) (BENDLE et al, 2015). O jogador faminto, sedento ou simplesmente em busca de descanso torna-se, neste momento, consumidor potencial. O grande número de adeptos nesta circunstância faz com que o Pokémon Go seja visto como um potencial promotor de vendas. 
Uma das formas privilegiadas para a Niantic de monetizar o jogo, já anunciada pela empresa, será a de implantar pontos de captura de seus monstrinhos em espaços comerciais que patrocinem pokéstops ou ginásios remunerando-a por isso. A mídia internacional já noticia o pacto entre a Niantics e a rede Mc Donald's do Japão pelo qual as 3.000 lojas japonesas da cadeia de fast food se transformam em pokestops ou ginásios. Segundo o site da Advertising Age (magazine especializado em marketing e mídia fundado em 1930) a expectativa quanto ao sucesso de tal acordo já fez com que as ações do McDonald's do Japão, após declínios em 2014 e 2015, voltassem a ter alta. Ao notar que as vendas das lanchonetes japonesas da rede subiram $27 \%$ baseadas em promoções com lanches que incluíam brinquedos relacionados aos pokémons e com o aumento de afluência gerado pelo jogo (ADVERTISING AGE, 2016).

\section{PROMOÇÕES NO SETOR DO TURISMO}

O acordo Niantic-McDonalds abre perspectivas futuras de negócios com outras empresas ligadas ao turismo e ao setor de alimentos e bebidas. Sendo parte das características do jogo o fato de os pokémons não serem distribuídos uniformemente pelas cidades, estes se concentram mais em metrópoles ou capitais, são mais raros em cidades pequenas e praticamente ausentes no meio rural (TECHTUDO, 2016). Estando o jogo articulado sobre a plataforma do Google Maps a Niantic está providenciando as adaptações técnicas e operacionais que permitirão redefinir a localização de seus pokéstops e ginásios de forma a possibilitar a venda de patrocínios para empresas em outros países (TECHTUDO, 2016). A esse respeito o CEO da Niantic John Hanke, expressou durante entrevista ao Financial Times que o patrocínio de lugares turísticos - ou querendo virar turísticos- será num futuro próximo uma das grandes fontes de renda de sua empresa. De acordo com Hanke a condição de ser um pokéstop ou um ginásio poderá ser garantia novos fluxos turísticos com tamanhos proporcionais à raridade dos monstrinhos presentes (VIGNON, 2016). Em troca do investimento feito, empresas teriam clientes potenciais atraídos para seus pontos de venda.

Fora do acordo Niantic-McDonald's, instituições de outras partes do mundo já estão captando jogadores-consumidores para suas dependências. Até o momento, são estas as que foram contempladas com pokéstops ou ginásios dentro ou nas cercanias de suas dependências de forma fortuita, sem qualquer interferência comercial (VIGNON, 2016). 
No ramo do turismo, exemplificados mais abaixo, destinos, atrativos turísticos e empresas já propagam na mídia sua condição de ponto interessante de captura de pokémons. Somam-se a estes, alguns serviços direcionados especificamente aos jogadores.

A cidade de Rouen na França, um destino turístico, está convidando os jogadores para descobrir o seu patrimônio cultural. Para isso propõe diversos roteiros. O próprio escritório de turismo local a ser visitado para consulta e informação é um pokestop (VIGNON, 2016).

A cidade de Nimes, no mesmo país criou o Pokebus, confortável ônibus ao custo de 5 Euros no qual é possível visitar pontos turísticos como os monumentos romanos "Maison Carrée" ou "Les Arenes". Os jogadores são convidados a "encher o tanque" de pokémons, fazer eclodir seus ovos ou participar de desafios em grupos nos Ginásios. Com a promoção, a cidade espera incentivar novos turistas a visitar a cidade (VIGNON, 2016).

Em Paris, a própria Torre Eifel está agora avisando os turistas, na sua conta Twitter, que podem ser encontrados nos seus arredores alguns pokémons raros (VIGNON, 2016).

$\mathrm{Na}$ Espanha a operadora de turismo Junior Travel publicou anúncios com vistas a recrutar guias para grupos de trinta jogadores de uma cidade a outra da Espanha. Receberam uma candidatura ao posto a cada 4 minutos em média declarou Antônio Barragam, gerente da operadora à AFP (VIGNON, 2016).

Ainda na Espanha a sociedade Felices Vacaciones propôs a seus clientes um circuito de Safari Pokemon Go nos Estados Unidos por 1.695 euros para captura de monstrinhos em Las Vegas, São Francisco e Nova Yorque (VIGNON, 2016).

No Brasil, o hotel Renaissance de São Paulo, contemplado com um ginásio Pokémon em suas dependências, lançou uma promoção visando atrair jogadores. $\mathrm{O}$ cliente que capturar um monstrinho na área do bar, postá-lo na rede social (\#rendo) e mostrar a publicação no bar situado junto à entrada e recepção do hotel, tem direito a $20 \%$ de desconto em suas bebidas. Tal promoção além de atrair clientes jogadores visa igualmente manter a empresa atualizada e vinculada aos assuntos da comunidade de acordo com a filosofia corporativa. Não havia por ocasião da visita e entrevista efetuada, contabilidade sobre o número de clientes participantes (Entrevista com Milla E. Salvador, "Navigator" - denominação do hotel para o cargo equivalente a "concierge" - em 15/09/2016). 
O curitibano Rogério Oliveira criou o Pokémon Tour Curitiba especializado em levar crianças para a procura de monstrinhos. Rogério monta grupos de 4 crianças, as quais busca e devolve em casa após o passeio. Trabalha com grupos pequenos para poder estar atento aos pequenos e garantir a segurança da operação. Os passeios duram até 3 horas a escolher entre 3 diferentes turnos por dia e as crianças capturam em média de 30 a 40 monstrinhos. O preço foi calculado por Rogério com base na taxa cobrada pela hora de playground em um shopping center local que é de 50 reais por hora. Segundo o autor, foram efetuados 10 tours de caça aos pokémons nas duas primeiras semanas de atividades (EXAME.COM, 2016).

A empresa de taxis Easy Taxi realizou uma promoção durante o mês de julho 2016 para promover seu serviço EasyGo de motoristas particulares, destinado a concorrer com o Uber. No aplicativo da Easy Taxi as fotos que identificam os motoristas foram substituídas por imagens de pokémons. Descontos de $\mathrm{R} \$ 5,00$ a $\mathrm{R} \$ 15,00$ eram concedidos de acordo com a raridade do Pokemon envolvido. Para ter direito ao desconto, porém, o passageiro deveria compartilhar uma imagem da tela de seu celular a qual mostrava o pokémon "capturado" (O ESTADO DE SÃO PAULO, 2016).

\section{PROMOÇÕES NO SETOR DE ALIMENTOS E BEBIDAS}

A peculiaridade do jogo, em que seus adeptos caminham e passam longos períodos fora de casa faz com que os jogadores se tornem clientes potenciais do setor de alimentação fora do lar. Empresas de consultoria em negócios do setor como a Marketing4restaurants já aconselham medidas que podem ser tomadas de forma a incrementar a exposição de empreendimentos de alimentos e bebidas nas redes sociais assim como aumentar o número de seus clientes (MARKETING4RESTAURANTS, 2016):

1. Divulgar às pessoas que seu restaurante é um Pokestop ou Pokemon Gym.

2. Ofereçer WI Fi grátis e estações para carregamento de baterias.

3. Incentivar os jogadores para que entrem em seu restaurante. Isso ajudara a obter novos clientes além de aprovação e "curtidas" nas redes sociais.

4. Filmar os jogadores de Pokémon Go apreciando o jogo ao lado de um prato ou café. Isto pode funcionar bem no Facebook Live. 
5. Estimular a postagem de vídeos e filmes feitos pelos jogadores nas redes sociais oferecendo um brinde ou desconto para incentivar o compartilhamento.

6. Recompensar clientes por fotos em seu restaurante.

7. Usar "lures" para aumentar o número de pokémons em seu pokestop.

Simultaneamente o site da Forbes (ZHU, 2016) recomenda:

1. Tire proveito dos Pokestops da redondeza.

2. Coloque "lures" durante todo o dia.

3. Organize encontros de pessoas em torno do jogo.

4. "Entre na onda”. (Ofereça brindes àqueles que capturam pokemons em sua loja).

5. Esteja atento ao lançamento de patrocínio de pokéstops pela Niantic.

Sem qualquer acordo com a Niantic no modelo ocorrido com a McDonalds Japão, diversas promoções do setor já aparecem na mídia:

O restaurante Maxwell's Bar and Grill de Londres encarregou um funcionário de comprar e distribuir "lures" ao redor do restaurante com a finalidade de atrair passantes. O proprietário afirma ter tido um retorno de 44 liras para cada investida em iscas o que resultou em um aumento de cerca de $26 \%$ na receita (ANTHONY, 2016).

A rede americana Capriotti's Sandwich ofereceu a seus consumidores um sanduiche grátis para quem postasse na internet um pokémon capturado em suas dependências. Tal promoção visa a incentivar o consumo de sanduíches, além de promover publicidade da casa que, graças a um programa de fidelidade, traz o jogador de volta ao estabelecimento.

A Down N'Out de Sydney, Austrália, lançou 3 hamburgueres inspirados em monstrinhos do jogo: Pikachu Burger, Charmander Burger e Bulbasaur Burger lançou um desafio: a primeira pessoa que postasse uma selfie sua junto com o pokémon escondido no centro da cidade no site Foodora (especializado em pedidos via internet para restaurantes e associada ao Down N'Out nesta promoção) ganharia um hambúrguer grátis entregue a domicílio (INGRAM, 2016). Segundo a publicação da empresa no Facebook, a promoção esgotou os estoques de pokeburgers no almoço do primeiro dia e fez com que a empresa reservasse outras 100 unidades extras para o jantar (INGRAM, 2016). 
O restaurante Poulet Poulette de Paris oferece 10\% de desconto sobre hambúrgueres quando o cliente apresenta uma postagem no Facebook mostrando o monstrinho Roucool na calçada em frente ao restaurante (DIGONNET, 2016).

O restaurante Les deux pieds sous la table de Aurillac, França (contemplado com uma estrela do guia Michelin) visando atrair jogadores, faz publicidade com apoio de fotos que indicam a presença de pokémons em uma praça situada nas cercanias do estabelecimento (DIGONNET, 2016).

Em São Paulo o autor, a partir da informação obtida com um jogador do parque Ibirapuera, visitou a pizzaria Soggiorno de Alphaville que brinda com uma pizza brotinho qualquer cliente que deposite "lures" no pokéstop situado nas dependências da pizzaria. Ao colocar lures no pokéstop a informação aparece igualmente no computador do estabelecimento. Identificado o jogador que efetuou a operação este tem direito ao brinde.

Conforme apurado em entrevistado feita pelos autores, são numerosos os clientes que frequentam o estabelecimento devido à promoção ainda que não haja uma contabilidade oficial a respeito. Como exemplo, a funcionária cita o caso de um menino que aparece a cada semana atraído pelo jogo e pela promoção trazendo com ele os avós que consomem e geram receita extra para o estabelecimento (Entrevista com a garçonete responsável pela promoção Paloma Oliveira em 7 de setembro de 2016).

A característica de jogo baseado em deslocamento dos jogadores propiciou igualmente, promoções em outros tipos de empreendimentos.

\section{CONCLUSÃO}

O fenômeno Pokémon Go caracterizado pelo recorde de downloads amplamente divulgado pela mídia eletrônica acompanha a tendência observada de crescimento exponencial dos jogos eletrônicos desde o lançamento de seu primeiro exemplar em 1972.

A diferença mais expressiva observada neste jogo deve-se às características da nova tecnologia empregada a qual induziu sua utilização fora dos espaços internos habituais dos jogos 
eletrônicos, ao mesmo tempo em que instigou os jogadores para a atividade física e a sociabilidade não virtual.

A partir do lançamento do jogo verificou-se que milhares de jogadores passaram a caminhar pelos espaços externos de suas cidades ou cidades vizinhas. Assim fazendo, tornaramse tais jogadores clientes potenciais para diversos negócios entre eles, aqueles relacionados ao turismo e ao fornecimento de alimentos e bebidas.

Sites ligados à mídia tradicional especializada em negócios anteveem possibilidades para empresas de tirar proveito do fenômeno verificado. Observou-se com a ajuda de exemplos pontuais no exterior e no Brasil que, embora ainda não se disponibilizem contabilidades precisas dos resultados o fenômeno tem sido explorado pelo marketing de diversas empresas buscando a captação desses novos clientes potenciais.

Pode-se inferir após o sucesso de adesões ao Pokémon Go que outros jogos explorando a realidade aumentada deverão aparecer no futuro levando jogadores para as ruas. $\mathrm{O}$ real potencial do impacto que estes novos estilos de jogos trarão para o comercio deverá aparecer com a contabilização mais precisa dos resultados obtidos.

\section{REFERÊNCIAS}

ADVERTISING AGE. McDonald's Japan Posts Profit Boosted by Pokémon Go Partnership. 9/08/2016. Disponível em: http://adage.com/article/cmo-strategy/mcdonald-s-japan-postsprofit-boosted-pok-mon/305388/. Acesso em 20/09/2016

ANTHONY, Sebastian. London restaurant drops Pokémon Go lures, revenues go up 26\% 22/7/2016, 10:21. ArsTECHNICAUK. Disponível em: http://arstechnica.co.uk/gaming/2016/07/london-restaurant-drops-pokemon-go-lures-revenuesgo-up-26/. Acesso em 30/09/2016

AZUMA, R. A Survey of Augmented Reality. Presence: Teleoperators and Virtual Environments, v .6, n.4, p.355-385, 1997.

BENDLE, Neil et al. The Alibaba Group and online to off-line (O2O) sales. Harvard Business publishing. 10/07/2015. Disponível em: https://cb.hbsp.harvard.edu/cbmp/product/W15286PDF-ENG. Acesso em: 20/09/2016. 
BOLDRINI, Thayse. Novidades para quem joga Pokémon Go. Pernanbuco.com, Comentários. 8/09/2016, 16:08 Disponível em:http://www.joaoalberto.com/2016/09/08/novidades-paraquem-joga-pokemon-go/ . Acesso em 10/09/2016

DENCKER, Ada; VIÁ, Sarah. Pesquisa empírica em ciências humanas. (com ênfase em comunicação). São Paulo: Futura, 2001 O método de observação 143 a 154

O papel da metodologia científica 45 a 51

DIGONNET, Anays. Pokémon Go : une aubaine pour attirer plus de monde dans son restaurant. 25/07/2016. Disponível em: http://blog.zenchef.fr/le-jeu-pokemon-go-une-aubaine-pour-attirerplus-de-monde-dans-son-restaurant. Acesso em: 03/10/2016.

EXAME.COM. Como os brasileiros estão ganhando dinheiro com o Pokémon GO

18/08/2016. Disponível em: http://exame.abril.com.br/pme/noticias/como-os-brasileirosestao-ganhando-dinheiro-com-o-pokemon-go. Acesso em: 19/09/2016

FERREIRA, Matheus. Indústria de games supera o faturamento de Hollywood. Setembro, 16. Disponível em http://www.webnoticias.fic.ufg.br/n/68881-industria-de-games-supera-ofaturamento-de-hollywood. Acesso em 31 agosto 2016

HAMANN, Renan. O que é e como fazer para chocar ovos. Tecmundo. 04 AGO 2016. Disponível em: http://www.tecmundo.com.br/pokemon-go/108069-pokemon-go-o-que-e-comofazer-chocar-ovos.htm. Acesso em 15/09/2016.

IBOPE NOTICIAS. Conheça as principais características de quem joga videogame no Brasil. 17/08/2012 Disponível em: http://www.ibope.com.br/pt br/noticias/Paginas/Conheca-ascaracteristicas-de-quem-joga-videogame-no-Brasil.aspx. Acesso em 15/09/2016

INGRAM, Lauren. Sydney pop-up Down N Out has created Pokemon-themed burgers. In Mail On Line, Food and Drink. Disponível em: http://www.dailymail.co.uk/femail/food/article3754084/Down-N-creates-Pokemon-BURGERS.html\#ixzz4KjnxHPfY. Acesso: 19/09/2016

KENSKI, Rafael; AGUERRE, Gabriela; MAROJA, Rodrigo. Armas de diversão em massa. Superinteressante, São Paulo: Junho, 2003.

LEVY, Sophie. Pokémon Go: notre guide pour devenir le meuilleur dresseur. L'intern@ute. 6/10/16. Disponível em: http://www.linternaute.com/hightech/jeux-video/1320224-pokemongo-evolution-pokepieces-liste-de-pokemon-le-guide-a-suivre-pour-savoir-commentjouer/\#pokeball-pokestop-pokepiece-definition. Acesso em 10/10/2016

MADIGAN, James H. Getting Gamers. The psychology of video games and their impacto on the people who play them. 08/2016. Disponível em: https://books.google.com.br/books?id=vDaCCgAAQBAJ\&pg=PA3\&lpg=PA3\&dq=arena+stap le+center+com+gamers+em+2013\&source=bl\&ots=4jLo1p_r1m\&sig=X6d5fK4LqbBIgllojpo CiCmsBBk\&hl=pt. Acesso em 02/09/2016 
MARKETING4RESTAURANTS. Pokemon Go Marketing for your Restaurant. 15/08/16. Disponível em: https://marketing4restaurants.com/pokemon-go-marketing-for-your-restaurant/. Acesso em 28/09/2016.

MASSARANI, Sandro. Pokemón e suas origens no videogame. In. Além do cotidiano. Texto original da revista Neo Tokyo ano 2007. Disponível em: http://www.massarani.com.br/fghqpokemon-gameboy.html. Acesso em 17/09/2016.

MATTAR, F. Pesquisa de marketing. Volume I Metodologia e Planejamento. São Paulo: Ed. Atlas. 1998. P. 132

O ESTADO DE SÃO PAULO. Redação link. App de táxi recorre a 'Pokémon Go' para dar descontos. 31/07/2016. 3:00 hs. Disponível em: http://link.estadao.com.br/noticias/culturadigital,app-de-taxi-recorre-a-pokemon-go-para-ar-descontos,10000065870. Acesso em $10 / 09 / 2016$

OLIVEIRA, Miguel. Como encontrar Pokémons raros em Pokémon Go. O Vicio. 6/08/2016 Disponível em: http://ovicio.com.br/como-encontrar-pokemon-raros-em-pokemon-go/ Acesso em $12 / 09 / 2016$.

PEREZ, Sarah. Pokémon Go becomes the fastest game to ever hit $\$ 500$ million in revenue. In: Tech Crunch. 08/09/2016. Disponível em https://techcrunch.com/2016/09/08/pokemon-gobecomes-the-fastest-game-to-ever-hit-500-million-in-revenue/. Acesso em 13/09/2016.

POKEMON BRASIL. Disponível em: http://www.pokemongobrasil.com/ Acesso em $18 / 09 / 2016$

RAMOS JR. D. Video-games facilitam o aprendizado do inglês. Tecmundo, Video Game e Jogos. 09 NOV 2011 - 19H51 Disponível em : http://www.tecmundo.com.br/video-game-ejogos/15206-video-games-facilitam-aprendizado-do-ingles.htm. Acesso em 01/09/2016

SANTOS, Marcel. Como jogar Ingress, o game para Android que utiliza elementos do mundo real. Techtudo. 27/06/2013 8:00. Disponível em: http://www.techtudo.com.br/dicas-etutoriais/noticia/2013/06/como-jogar-ingress-o-game-para-android-que-utiliza-elementos-domundo-real.html. Acesso em 04/09/2016

SCHMIDT, Emanuel. Saiba quais são os videogames mais vendidos de todos os tempos. Techtudo. 28/11/2015. Disponível em:http://www.techtudo.com.br/listas/noticia/2015/11/saibaquais-sao-os-videogames-mais-vendidos-de-todos-os-tempos.html. Acesso em 05/09/2016

SILLIS, Bem. Os incríveis números do Pokémon Go. REDBULL.PT. 23/08/2016. Disponível em:http://www.redbull.com/pt/pt/games/stories/1331813568090/os-incr\%C3\%ADveis-

n\%C3\%BAmeros-do-pok\%C3\%A9mon-go. Acesso em 12/09/2016. 
STATISTA, The Statistic Portal. Age breakdown of video game players in the United States in 2016. 2016. Disponível em: http://www.statista.com/statistics/189582/age-of-us-video-gameplayers-since-2010/. Acesso em 15/09/2016

TAKAHASHI, Dean. The acidental history of Niantic's Pokemon Go, as told by John Hanke. Venture beat. 10/08/2016 10:05 am, Disponível em: http://venturebeat.com/2016/08/10/theaccidental-history-of-niantics-pokemon-go-as-told-by-john-hanke. Acesso em 04/09/2016

TECH TUDO. Entenda como Pokemon Go escolhe gyms e pokestops com casos curiosos. 2016. Disponível em: http://www.techtudo.com.br/noticias/noticia/2016/07/entenda-como-pokemongo-escolhe-gyms-e-pokestops-com-casos-curiosos.html. Aceso em 10/09/2016

TEIXEIRA JR.. Sérgio. É muito mais que uma brincadeira. In: Revista Exame edição 1119, 17/08/2016. p. 100 a 108.

UAI.COM. Pokemon go tem mais de 50 milhões de usuários no Brasil em menos de 24 horas. 04/08/2016. Disponível em: http://www.uai.com.br/app/noticia/games/2016/08/04/noticiasgames, 182774/pokemon-go-tem-mais-de-50-milhoes-de-usuarios-no-pais-em-menos-de-

24h.shtml. Acesso em 15/09/2016

UOL SELECT GAME. Os jogos eletrônicos e seu impacto na sociedade. 2006. Disponível em: http://selectgame.gamehall.uol.com.br/os-jogos-eletronicos-e-seus-impactos-nasociedade/amehall.uol.com.br/os-jogos-eletronicos-e-seus-impactos-na-sociedade. Acesso:05/09/2016.

VIGNON, Émile. Pokemon Go: Comment les pros du tourisme se prennent au jeu. 20/08/2016 9:32 hs. L'Écho Touristique. Disponível em: http://www.lechotouristique.com/article/pokemongo-comment-les-pros-du-tourisme-se-prennent-au-jeu,83852. Acesso em 12/09/2016

VINHA, Felipe. Pokémon Go: entenda para que servem os itens e como funcionam. TECH TUDO. 14/07/2016. Disponível em: http://www.techtudo.com.br/dicas-etutoriais/noticia/2016/07/pokemon-go-entenda-para-que-servem-os-itens-e-comofuncionam.html. Acesso em 18/07/2016

ZHU, Yehong. 5 Brilliant Ways Restaurants Are Using Pokémon Go To Level Up Sales. Forbes, 16/07/2016. Disponível em http://www.forbes.com/sites/yehongzhu/2016/07/16/5-brilliantways-restaurants-are-using-pokemon-go-to-level-up-sales/2/\#7da8cace7e76. Acesso em 16/09/2016.

\footnotetext{
Recebido em: 21/10/2016

Reavaliado em: 02/11/2016

Aceito em: 09/11/2016
} 